\title{
Risks and benefits of lethal male fighting in the colonial, polygynous thrips Hoplothrips karnyi (Insecta: Thysanoptera)
}

\author{
Bernard J. Crespi \\ Museum of Zoology and Department of Biology, University of Michigan, Ann Arbor, MI 48109-1079, USA
}

Received June 3, 1987 / Accepted November 20, 1987

Summary. Males of Hoplothrips karnyi (Hood) (Insecta: Thysanoptera), a colonial fungus-feeding thrips, fight each other in defense of communal egg mass sites, where they mate with females that come to oviposit. Fighting males stab each other with their enlarged, armed forelegs and hit each other with their abdomens. Escalated fights occur between large males of similar size. Fights are often lethal; males that died during observations fought more frequently than other males, were stabbed more often and more severely than other males, and were relatively large, but somewhat smaller than their opponents. Large males tend to win fights and guard egg masses, and they secure about $80 \%$ of last matings before ovipositions. Guarding males apparently assess female reproductive condition by putting their forelegs partially around females' abdomens; guarding males, but not nonguarding males, mate preferentially with females that have yet to oviposit. Non-guarding males mate with females away from egg masses, sneak matings at egg masses, and occasionally challenge guarding males. Challenges tend to follow matings by non-guarding males at egg masses. Each of four observed or inferred takeovers was followed by the death of the guarding male that lost. Male fighting strategies are discussed in terms of the consistency of lethal fighting with game theory models. Guarding males appear to pursue a classical "hawk" strategy of "escalate until injured or victorious". This strategy may be advantageous because only large males become guarders, the mating success of guarders greatly exceeds that of non-guarders, and high population viscosity ensures that benefits from killing an opponent accrue directly to guarders. The occurrence of challenges by large non-guarders implies that fighting ability and resource value asymmetries between males change over time; such changes may result from the ener- getic costs of guarding, injury to guarding males, or depletion of guarding males' supply of sperm.

\section{Introduction}

Game theory models of animal conflict were originally developed to explain the rarity of damaging and lethal combat (Maynard Smith and Price 1973; Maynard Smith 1974). These models demonstrated that populations in which animals fight until injured or victorious can be invaded by individuals that assess their fighting ability relative to their opponents, evaluate the resource under contention, and fight only when expected net benefits exceed costs. Although empirical studies have established the ubiquity of assessment of fighting ability (Davies and Halliday 1978; Clutton-Brock et al. 1979; Sigurjonsdottir and Parker 1981; Arak 1983; Austad 1983; Ramer et al. 1983; Suter and Keiley 1984; Thornhill 1984; Otronen 1984; Robinson 1985; Crespi 1986a, b) and resource value (Rand and Rand 1976; Riechert 1978; Ewald 1985), measuring the actual costs and benefits of fighting has proven to be much more difficult (but see Austad 1983; Ewald 1985).

The most obvious costs of fighting are injury and death. However, there have been few gametheoretic studies of animals that routinely kill one another. Lethal fighting has been described in mites (Potter et al. 1976; Timms et al. 1980; Cowan 1984), fig wasps (Hamilton 1979), parasitic wasps (Matthews 1975; Van den Assem et al. 1980; Godfray 1987), gall aphids (Aoki and Makino 1982), queen honeybees (Seeley 1985), spiders (Austad 1983), beetles (Tiemann 1967), anurans (Kluge 1981), and ungulates (McHugh 1958; Wilkinson and Shank 1976; Clutton-Brock et al. 1979; 
Clutton-Brock 1982). Two hypotheses may explain the distribution and prevalence of lethal fighting: either lethal fights occur when assessment mechanisms are inadequate or irrelevant (e.g., Parker and Rubenstein 1981; Suter and Keilly 1984), or species with lethal fighting share particular social or ecological conditions that cause the rewards of lethal fighting to offset its costs. If the latter hypothesis is correct, species with lethal fighting might be expected to show especially well-developed mechanisms for assessment of fighting ability, resource value and ownership status (e.g., CluttonBrock et al. 1979; Austad 1983).

The purpose of this paper is to describe the social behaviour, mating system and male mating tactics of the colonial thrips Hoplothrips karnyi, in order to explain in game-theoretic terms its high frequency of lethal male fighting. Thrips are haplodiploid insects exhibiting sexual dimorphism in foreleg development (Ananthakrishnan 1979, 1984), female-biased sex ratios (Stannard 1957; Lewis 1973; Hamilton 1979; Crespi unpubl.), and frequent overlap of generations. $H$. karnyi is a black, heavily-sclerotized, wing-polymorphic thrips about $3 \mathrm{~mm}$ long that lives on shelf fungi and feeds on mycelium (Stannard 1968). Males possess enlarged forelegs armed at the apices with pointed fore-tarsal teeth that are used for fighting in defense of communal female oviposition areas. Male fighting has been described in two other species of thrips, Hoplothrips pedicularius (Crespi 1986a) and Elaphrothrips tuberculatus (Crespi 1986b), neither of which provides direct evidence for male mortality from combat. However, in $H$. karnyi lethal fighting appears to be common. If game theory reasoning can explain cases of deadly combat as well as its absence, its status as a unifying framework for the study of animal conflict will be enhanced (see also Clutton-Brock et al. 1979; Austad 1983).

\section{Methods}

\section{Collection and observation}

Hoplothrips karnyi was collected at three sites: (a) Washtenaw Co., Michigan (from a large colony), maintained in the lab at $22^{\circ} \mathrm{C}, 16 \mathrm{~L}: 8 \mathrm{D}$ for several generations at a large population size ( $>200$ adults) on Polystictus versicolor fungus (colonies 1 and 2), (b) Livingston Co., Michigan, observed as field-collected adults (colony 3), and (c) Berrien Co., Michigan, observed as field-collected adults (colony 4). Males in colonies 1 and 2 had moulted to adulthood 3-6 days before observations were begun.

The thrips were observed in the $0.5-2 \mathrm{~mm}$ space between pieces of sassafras (Sassafras albidum) wood containing Polystictus versicolor mycelium and clear hard plastic. In colonies
1 and $2,8 \times 3 \mathrm{~cm}$ pieces of wood were put in the bottom of $8 \mathrm{~cm}$ diameter round plastic petri dishes, and in colonies 3 and 4 , rectangles of hard plastic, $3 \times 6 \mathrm{~cm}$ and $4 \times 7 \mathrm{~cm}$ respectively, were sealed at the edges with clay against the wood. Each colony contained six males and 8-10 females, individually marked on the thoraces with Testor's enamel paint. Colonies of approximately this size and composition have been collected in the field (Crespi unpublished data). Observations were conducted between 1000 and $2300 \mathrm{~h}$ at $20-22^{\circ} \mathrm{C}$ under low light intensity with a dissecting microscope. During five to six consecutive days, the colonies were observed for $2-10 \mathrm{~h}$ daily, for a total of $40 \mathrm{~h}$ of observation on each colony.

The identities of all individuals engaging in copulations, ovipositions, male-male interactions, and several other behaviours (described below) were recorded within $4 \mathrm{~mm}$ (the body length of gravid females) of egg masses. In addition, in colony 4 the identities of females at oviposition sites were recorded every $5 \mathrm{~min}$. After observation, male femoral length was measured to the nearest $0.001 \mathrm{~mm}$ with a LASICO movable hairline ocular micrometer on a WILD M8 microscope at 50 -fold magnification. So that the size distributions of males and females could be compared, the fore-femoral lengths of 170 field-collected individuals from Washtenaw Co., Michigan, were also measured.

\section{Analysis}

Because only four winged males were included in this study, the data were analysed with respect to male size but not wing morph. Winged and wingless males differ in size and shape (Crespi in prep.), but their fighting and mating behaviours are not clearly distinguishable (Crespi pers. obs.).

Statistics were computed using the Michigan Interactive Data Analysis System (Fox and Guire 1976), and all tests were two-tailed. Since the assumptions of normality and equal variances were generally not met, non-parametric tests were used. The $G$-test, a form of the $\chi^{2}$ test, was used for assessing independence.

Contingency tables depicting first-order transition frequencies between behaviours were used in analyses of whether or not males mated following "reverse-climb" behaviour (in relation to subsequent ovipositions), and of the effect of recent matings by non-guarding males on whether or not they subsequently challenged guarding males (see below). Slater (1973) describes the statistical assumptions underlying such transition matrix analyses; the most important assumption is stationarity, that is, constant unconditional probabilities of the behaviours. In the former analysis, this assumption was met in colonies 2,3 , and 4 (i.e., mating and oviposition rates remained roughly constant throughout the observations). In the latter analysis, potential non-stationarity was mitigated by including only observation periods ( $2-10 \mathrm{~h}$ in duration) during which challenges occurred. For this analysis, sample sizes in colonies 1 and 2 were too small for meaningful statistical analysis. Sets of $2 \times 2$ contingency tables were combined using the Mantel-Haenszel test (Snedecor and Cochran 1980, p. 212).

Data are presented as means \pm one standard deviation.

\section{Systematics}

The systematic position of Hoplothrips karnyi is somewhat uncertain; this thrips keys to Hoplothrips beachae in Stannard (1968), but actually belongs to the Hoplothrips karnyi (Hood) species complex, which comprises "a number of closely related and ill-defined species from North America and Europe" (L. Mound and J. Palmer, pers. comm.). The thrips observed in 


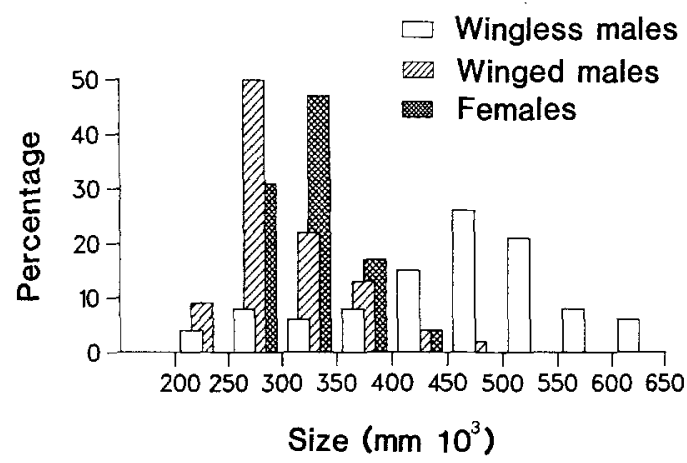

Fig. 1. Size (fore-femoral length) distributions for wingless males, winged males, and females of Hoplothrips karnyi. On average, males have larger forelegs than do females

this study were morphologically indistinguishable in taxonomic characters such as antennal colour, and different colonies interbreed freely. Voucher specimens have been deposited in the University of Michigan Museum of Zoology insect collection.

\section{Results}

Male and female fore-femoral length distributions

The fore-femoral length distributions of field-collected males and females are shown in Fig. 1. The fore-femora of males are larger (mean $=0.380 \pm$ $0.109, \quad n=100)$, than those of females $(0.321 \pm 0.034, n=70 ; P<0.05$, Mann-Whitney $U$ test), and are also more variable in size (non-parametric Levene test, $P<0.01$ ). The variation in male and female fore-femoral length for the observed thrips was similar to that found in these populations.

\section{Male fighting}

Males fought with two tactics: stabbing and wagging. Stabbing consists of one male grasping his opponent with his forelegs and squeezing, driving his pointed fore-tarsal teeth against his opponent's exoskeleton. During $135(98 \%)$ of 138 observed stabs the stabbing male grasped his opponent around the abdomen from the rear; in the other three cases stabs occurred head-to-head. The stabbing male's forelegs usually slipped off his opponent's body, apparently from the force of the grasping motion and the movements of the stabbed male. However, during five stabs the stabbed male was held securely around the abdomen, for $10 \mathrm{~s}$ to several minutes. Wagging involved jerking the abdomen sharply from side-to-side several times, and it usually occurred in conjunction with stab-

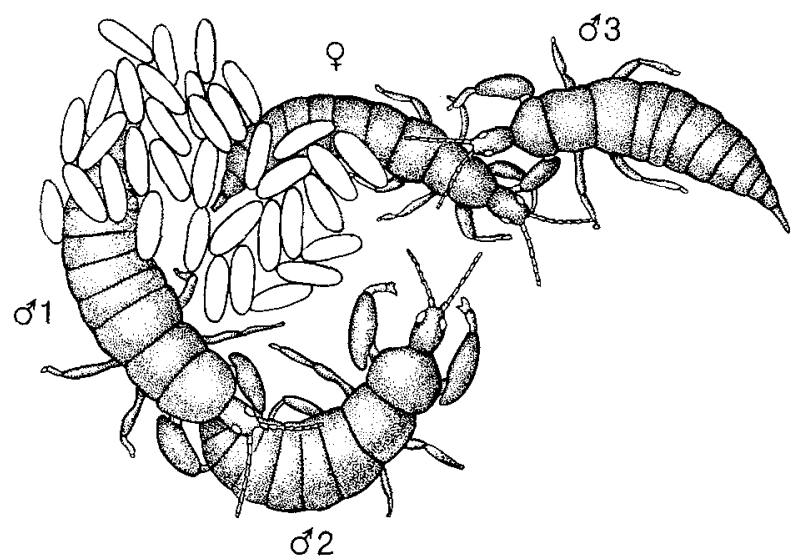

Fig. 2. Male fighting and sneaking behaviour at an egg mass area. Male 1 is stabbing male 2 , and male 3 is approaching a female in an attempt to sneak a copulation

bing by an opponent. During a typical fight males alternately grasped at their opponent's abdomen and wagged when their opponent attempted to grasp them. Sometimes males grasped one another simultaneously, moving around in a circle, or wagged at each other back-to-back. Fights lasted from several seconds to $16 \mathrm{~min}(n=15$ fights in which both males stabbed), and fights ended with the retreat of one male from the egg mass area, often after he had been stabbed. Escalated fights are defined here as fights in which each combatant stabbed his opponent, and non-escalated fights are defined as comprising stabs by one male and wagging (rather than immediate retreat) by the other.

\section{Behaviour of guarding and non-guarding males}

Guarding males remained on or near communal egg masses and attacked males with whom they came into contact (Fig. 2). When females were present at egg masses, guarding males usually walked around the egg mass area, climbing onto the females' backs and mating frequently. Ovipositing females mated with guarding males an average of $1.5 \pm 1.8$ times prior to ovipositions ( $n=487$ matings in 342 ovipositions). Guarding males sometimes $(n=61)$ rubbed the last few segments of their abdomen against the substrate next to the eggs for a few seconds; this behaviour may be associated with the abdominal glandular area found in male thrips (Bode 1978).

Non-guarding males mated with females away from egg masses, made occasional incursions into egg mass areas to attempt matings there, and avoided the guarding male by running from physical contact with him. In $859(53 \%)$ of 1614 encounters between guarding males and non-guard- 
ing males, guarding males did not respond to the contact (aversions), whereas in $755(47 \%)$ of the encounters guarding males chased non-guarding males for $1-20 \mathrm{~mm}$ and attempted to stab them (attacks). When non-guarding males were being chased they sometimes lifted the end of their abdomen up at an angle, preventing the guarding males from stabbing them. However, in $59(8 \%)$ of the attacks the guarding male stabbed the nonguarder.

Aversions and attacks interrupted 128 initiated mating attempts by non-guarders, which represented $13 \%$ of 961 total initiated matings by nonguarders. Apart from interruption of matings, the effect of aversions and attacks was to keep nonguarders out of egg mass areas. Contact between non-guarding males usually elicited neither attacks nor aversions. However, large non-guarders sometimes chased smaller ones for short distances and non-guarders occasionally avoided one another when near the egg mass. Challenges to the guarding male by non-guarders are described below.

\section{Mating and oviposition}

Females usually fed on fungal mycelium away from oviposition sites. When they were ready to oviposit, females walked to an egg mass and began alternately tugging gently at the eggs with their forelegs, walking slowly around the egg mass area, lifting their abdomens up at a $30-40^{\circ}$ angle with the apex probing against the eggs or the edge of the egg mass with short side-to-side motions, and remaining still. Females spent an average of $21.6 \pm 19.4 \mathrm{~min}$ at egg masses until oviposition, with an average duration of $8.2 \pm 5.8 \mathrm{~min}$ from the start of oviposition behaviour (tugging and probing at the eggs) until egg-laying $(n=82$, data from colony 4). Eggs were laid singly onto the edges of egg masses, usually at the site of the most recent prior ovipositions. After oviposition, females remained at egg masses for an average of $12.7 \pm 20.9 \mathrm{~min}(n=88, \quad$ median $=6 \mathrm{~min})$. The number of females at an egg mass varied from 0 to 8 , with a mean of $2.5 \pm 2.0$ females $(n=71$ scans at $30 \mathrm{~min}$ intervals in colony 4 ). In colonies $2-4$, all of the females were visibly gravid throughout the observations.

Mating occurred when a male contacted a female with his antennae, climbed onto her back, and inserted his genitalia. Females were not observed to reject mating attempts. Mating lasted from 8 to $42 \mathrm{~s}(19.2 \pm 4.1 \mathrm{~s}, n=436)$. After climbing onto a female, a male frequently turned toward the female's abdomen and put his forelegs partially
Table 1. Transition matrices showing the temporal relationships between male reverse-climb behaviour and subsequent copulation, in relation to whether or not females oviposited within the $20 \mathrm{~min}$ following the reverse-climb. Following reverseclimbs, guarding males copulated preferentially with females that had yet to oviposit on their current visit to the egg mass area $(P<0.001$, Mantel-Haenszel test); however, for nonguarding males, copulations following reverse-climbs in egg mass areas were apparently independent of subsequent ovipositions $(P>0.50)$

\begin{tabular}{|c|c|c|c|c|c|c|c|}
\hline \multirow{2}{*}{$\begin{array}{l}\text { Col- } \\
\text { ony }\end{array}$} & \multirow{2}{*}{ Copulation } & \multicolumn{3}{|c|}{ Guarding } & \multicolumn{3}{|c|}{ Non-guarding } \\
\hline & & Ovp. & $\begin{array}{l}\text { No } \\
\text { ovp. }\end{array}$ & G & Ovp. & $\begin{array}{l}\text { No } \\
\text { ovp. }\end{array}$ & $\mathrm{G}$ \\
\hline \multirow[t]{2}{*}{2} & $\begin{array}{l}\text { Copulation after } \\
\text { reverse-climb }\end{array}$ & 41 & 44 & $7.76^{*}$ & 9 & 27 & 0.58 \\
\hline & $\begin{array}{l}\text { No copulation after } \\
\text { reverse-climb }\end{array}$ & 10 & 33 & & 4 & 8 & \\
\hline \multirow[t]{2}{*}{3} & $\begin{array}{l}\text { Copulation after } \\
\text { reverse-climb }\end{array}$ & 64 & 49 & $4.97 *$ & 9 & 40 & 0.00 \\
\hline & $\begin{array}{l}\text { No copulation after } \\
\text { reverse-climb }\end{array}$ & 18 & 30 & & 3 & 14 & \\
\hline \multirow[t]{2}{*}{4} & $\begin{array}{l}\text { Copulation after } \\
\text { reverse-climb }\end{array}$ & 33 & 25 & 2.32 & 2 & 24 & 1.10 \\
\hline & $\begin{array}{l}\text { No copulation after } \\
\text { reverse-climb }\end{array}$ & 7 & 12 & & 3 & 13 & \\
\hline
\end{tabular}

$* P<0.05$

around it, a behaviour that was called a "reverseclimb". The temporal relationship between ovipositions and reverse-climbs by guarding and nonguarding males was investigated by creating transition matrices for the transitions between mating or not mating after a reverse-climb, and whether or not females would oviposit in the next $20 \mathrm{~min}$ (the average time from female arrival to oviposition) (Table 1). Whether or not mating followed reverse-climbs depended upon the guarding status of males and if females had yet to oviposit during their current visit to the egg mass area. Guarding males mated preferentially with females that had not yet oviposited, whereas, for non-guarding males, mating decisions at oviposition sites were apparently independent of ovipositions. However, the proportion of females mated following reverseclimbs did not differ between guarders and nonguarders; guarders mated following $256(70 \%)$ of 366 reverse-climbs, and non-guarders mated following $111(71 \%)$ of 156 reverse-climbs.

\section{Male size, guarding status, and mating success}

Figure 3 shows the guarding status of males in the four colonies and the occurrences of fights. 

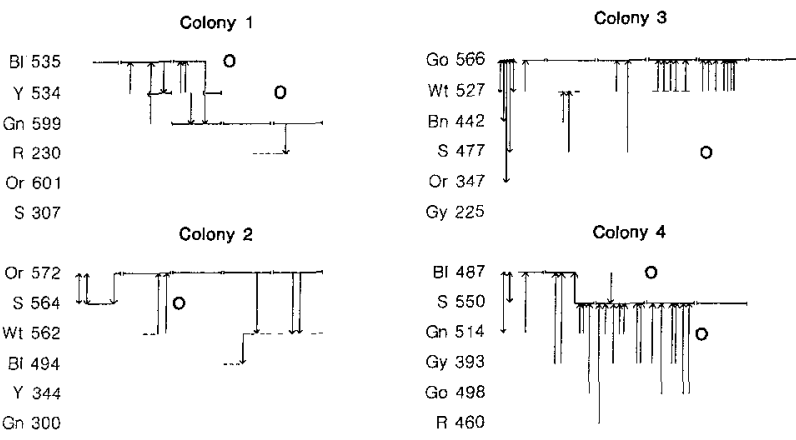

Fig. 3. Summary of male fighting and guarding behaviour in four colonies of Hoplothrips karnyi. Male identity and forefemoral length (in $\mathrm{mm} 10^{3}$ ) are shown at left. Solid horizontal lines represent times during which that male guarded an egg mass area, and dashed lines represent "sporadically-guarding" males. Double-headed arrows represent fights that occurred before one male became the guarding male at an egg mass area, single-headed arrows represent challenges, and open circles represent male deaths. See text for details

Colonies 1, 2, and 3 each contained two egg masses, although nearly all of the ovipositions occurred at only one of these at any given time. Guarding males are defined here as males that remained at an egg mass for at least four hours continuously, during which time they always attacked other males and were always avoided by them (except during challenges); by this definition eight males were guarders. In addition, four males remained at secondary egg masses for periods ranging from several minutes to several hours intermittantly. These "sporadically guarding" males did not consistently attack other males, nor were they consistently avoided by them.

Guarding males were significantly larger (femoral length $=0.551 \pm 0.033 \mathrm{~mm}, n=8$ ) than nonguarding males $0.420 \pm 0.116 \mathrm{~mm}, n=16 ; P<0.01$, Mann-Whitney $U$-test), and all of the guarding males were wingless. The copulation rate of males while guarding egg masses $(7.25 \pm 2.8$ copulations/ $\mathrm{h}, n=8$ ) greatly exceeded that of non-guarding males $(0.56 \pm 0.81$ copulations $/ \mathrm{h}, n=16 ; P<0.001$, Mann-Whitney $U$-test). Guarding males secured $1397(65 \%)$ of 2148 copulations at egg mass areas, and a higher proportion, $298(78 \%)$ of 380 last matings prior to ovipositions $(G=27.8, P<0.001)$.

Guarding may involve substantial energetic and injury costs. Guarding males could not feed without leaving the oviposition site (this is the usual situation in nature), and when females were present these males were usually much more active than non-guarding males; this suggests that guarding is energetically expensive. Males guarding egg masses engaged in fights significantly more fre- quently $(0.319 \pm 0.166$ fights/h, $n=8)$ than did nonguarding males $(0.059 \pm 0.104$ fights $/ \mathrm{h}, n=16 ; P<$ 0.001 , Mann-Whitney $U$-test). Guarding males were stabbed at more than twice the frequency $(0.308 \pm 0.265$ stabs $/ \mathrm{h}, \quad n=8)$ of non-guarding males $(0.116 \pm 0.156 \mathrm{stabs} / \mathrm{h}, n=16)$, but this difference was marginally non-significant $(0.05<P<$ 0.10, Mann-Whitney $U$-test). However, guarding status was associated with eventual death; four $(50 \%)$ of eight guarding males died during the observations, versus only two $(12.5 \%)$ of 16 nonguarding males $(G=3.85, P<0.05)$.

\section{Fights, challenges, and death}

Fights occurred in three circumstances: when guarding status was being established $(n=8)$, when two "guarding" males met $(n=6)$ (see below), and when non-guarding males challenged guarding males $(n=43)$. Fights between two non-guarding males took place during the initial few hours after males were put in the colonies, and involved relatively large males. Guarding males fought in two situations: when a guarding male went from his egg mass to that of another guarding or sporadically guarding male $(n=5)$, and when a guarding male left his egg mass to feed, during which time a non-guarding male took up residence there and fought with the original guarder upon his return $(n=1)$.

Challenges occurred throughout the observations, and were engaged in by relatively large males that had recently mated in egg mass areas. Nonguarding males that challenged guarding males at least once were larger (mean fore-femoral length $=$ $0.517 \pm 0.058, n=11$ ) than non-guarding males that did not challenge $(0.366 \pm 0.125, n=9 ; P<$ 0.01 , Mann-Whitney $U$-test; test excludes postguarding males and a male that only guarded). Non-guarding males were more than twice as likely to challenge guarding males if they had mated at the egg mass area within the last three min (Table 2); overall, $22(51 \%)$ of 41 challenges were closely preceded by such matings.

Two of the observed challenges (male Or challenging male $S$ in colony 2 and male $S$ challenging male $\mathrm{Bl}$ in colony 4) led immediately to takeovers, one takeover resulted from a guarding male challenging another guarding male and losing (male $\mathrm{Bl}$ fighting male $\mathrm{Gn}$ in colony 1), and one takeover was inferred (Male Y losing to male $\mathrm{Gn}$ in colony 1). The guarding males that lost died within $36 \mathrm{~h}$ of each takeover.

Fight intensity varied with male relative and absolute size. Pairs of males that engaged in at 
Table 2. Transition matrices showing the relationships between copulations by non-guarding males in relation to subsequent challenges to guarding males. If non-guarding males had copulated in the egg mass area within the 3 min prior to contacting the guarding males, they were more likely to challenge $(P<0.01$, Mantel-Haenszel test). To reduce bias against the null hypothesis, consecutive aversions and attacks within $1 \mathrm{~min}$ were pooled

\begin{tabular}{llllll}
\hline Colony & Copulation & $\begin{array}{l}\text { Chal- } \\
\text { lenges }\end{array}$ & $\begin{array}{l}\text { Aver- } \\
\text { sions } \\
\text { + attacks }\end{array}$ & $\begin{array}{l}\text { Per- } \\
\text { centage } \\
\text { challenges }\end{array}$ & $G$ \\
\hline 3 & Copulation & 9 & 42 & 0.18 & 3.3 \\
& No copulation & 6 & 76 & 0.07 & \\
4 & Copulation & 8 & 66 & 0.11 & 2.7 \\
& No copulation & 11 & 205 & 0.05 & \\
\hline
\end{tabular}

least one escalated fight were closer in size (femoral length difference $=0.039 \pm 0.027 \mathrm{~mm}, n=7$ ) than pairs of males that engaged in non-escalated fights $(0.123 \pm 0.106 \mathrm{~mm}, n=10)$, or pairs of males (one guarding and the other non-guarding) that did not fight $(0.175 \pm 0.121 \mathrm{~mm}, n=17 ; P<0.05$, KruskalWallis ANOVA). Males that engaged in escalated fights were also absolutely larger (mean fore-femoral length $=0.545 \pm 0.032 \mathrm{~mm}, n=10$ ) than males that engaged only in non-escalated fights $(0.426 \pm 0.102 \mathrm{~mm}, n=8)$, or males that did not fight $(0.379 \pm 0.141 \mathrm{~mm}, n=6 ; P<0.01$, KruskalWallis ANOVA).

Six $(25 \%)$ of the 24 males died during observations, whereas two $(6 \%)$ of 34 females died $(G=$ $4.33, P<0.05)$. There were several differences between males that died and survivors. Males that died: (1) had fought more frequently $(0.16 \pm 0.05$ fights $/ \mathrm{h})$ than survivors $(0.08 \pm 0.12$ fights $/ \mathrm{h} ; P<$ 0.05 , Mann-Whitney $U$-test), (2) were large, but somewhat smaller than their opponents (Fig. 4), (3) had been stabbed more often $(8.5 \pm 2.6$ stabs) than survivors $(4.8 \pm 6.4$ stabs; $P<0.05$, MannWhitney $U$-test), and (4) may have been stabbed more severely than survivors; four of the six males that died had been held by their opponent, whereas only one of the 14 survivors that was stabbed had been held $(G=7.65, P<0.01)$.

Two of the males that died showed clear signs of injury while still alive. Male $S$ in colony 3 had an indentation in the lateral edge of his abdomen $48 \mathrm{~h}$ before death, and male $\mathrm{Bl}$ in colony 4 had an injured right foreleg, and walked with a limp, $24 \mathrm{~h}$ before he died. Three other males that died (males $\mathrm{Bl}$ and $\mathrm{Y}$ in colony 1 , and male $\mathrm{S}$ in colony 2) wandered around the observation areas in an apparently disoriented manner before dying.

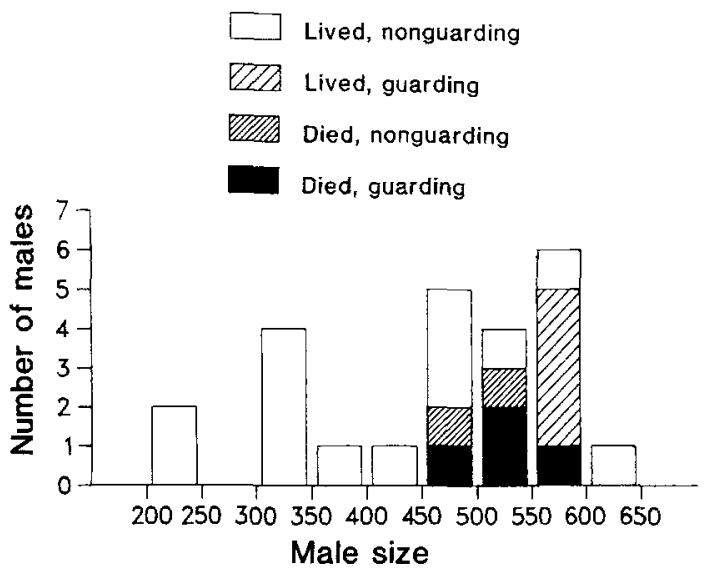

Fig. 4. The relationship between male size (fore-femoral length, in $\mathrm{mm} 10^{3}$ ), guarding status, and death. Males that died were large, but smaller than the largest males, and had usually guarded egg mass areas previously

\section{Discussion}

Hoplothrips karnyi males fight in territorial defense of oviposition sites. Non-territorial males adopt an alternative mating tactic of sneaking matings at oviposition sites and mating away from oviposition sites. Mating systems comprising a combination of territorial defense and sneak mating tactics have been described for a variety of insects (see Thornhill and Alcock 1983) and vertebrates (see Rubenstein 1980; Arak 1983; Dominey 1984). In $H$. karnyi, as in most other species, expression of the alternative tactics is conditional on body size; large size confers success in fights and acquiring a territory. Body size of $H$. karnyi males is determined primarily by food intake during the second (final) larval instar (Crespi in prep.).

The major benefit of territorial defense in Hoplothrips karnyi males in probably increased mating success relative to non-territorial males. Assessing differences between tactics in lifetime reproductive success, however, requires data on sperm competition patterns, sex ratio of the eggs laid (male eggs are unfertilised), and differential, strategy-dependent mortality in field colonies. Deviations from the common pattern of last-male sperm priority (Gwynne 1984), if they occurred here, would tend to equalise reproductive success between guarding and non-guarding males. Similarly, the increased mortality of guarding males relative to non-guarding males shown in this study represents a substantial cost to guarding that offsets its benefits.

The data linking fight frequency, occurrence and severity of stabs, relative male size, and injury 
with the death of six males suggest that these males died from wounds incurred in combat. The frequency of lethal fighting in field colonies is unknown. However, the observed deaths were probably not artifacts of laboratory conditions because: (1) wingless males clearly possess lethal weapons (their massive, armed forelegs), (2) males did not attempt to leave the colonies, although in colonies 1 and 2 they could have left, and (3) the observation conditions resemble the crevices under bark where colonies naturally occur. Moreover, the size class of males that died (large, but smaller than the largest males) is what one might expect if lethal fighting were normal. If the apparent size intermediacy of killed males is true in this case and common in other animals with severe fighting (and body size has non-zero heritability), such disruptive selection may help explain the evolution of male dimorphism (see Gadgil 1972; Hamilton 1979; Eberhard 1982).

Game theory models of animal conflict predict that individuals should assess the asymmetries in fighting ability, ownership status, and resource value that affect the outcome of conflicts (Maynard Smith 1982). Are Hoplothrips karnyi male mating tactics influenced by assessment of these asymmetries? Variation in fight occurrence and intensity with relative male size suggests that males assess their size relative to that of their opponents. However, the mechanism for such assessment is unclear; males evidently do not engage in assessment displays (Parker 1974; Crespi 1986 b) whereby contents can be settled without combat. Moreover, large absolute size is also associated with aggressiveness. This absolute size effect suggests either "assessment" by males of their own size (perhaps hormonally), or a link between size and other factors that promote fighting, such as mating frequency. Evidence for assessment of ownership status includes the well-developed sneaking behaviour of non-guarding males, and the tendency for escalation to occur when a guarding male goes from his oviposition site to that of another male (socalled owner-owner fights) (see Davies 1978; Krebs 1982). The data do not address directly the question of whether or not males assess resource value, defined as the difference in subsequent reproductive success between winning and losing a fight (Parker 1974). However, the temporal link between guarding males' reverse-climb behaviour, copulation, and subsequent oviposition suggests that guarding males may have information about the value of females and oviposition sites that nonguarding males lack. Thus, reverse-climbs may be viewed as a form of male "choice" (see Dewsbury
1982; Nakatsuru and Kramer 1982; Dewsbury and Sawrey 1984). Such behaviour, involving assessment of whether or not a female has yet to oviposit, or, perhaps, of the sex of the egg to be laid, might be expected where guarding males are limited not by access to females but by their rates of sperm production. This hypothesis could be tested by controlled matings followed by sperm counts.

Given that males assess fighting ability and ownership status, what fighting and mating strategies do guarding and non-guarding males pursue? Guarding males always attacked non-guarders, and in each of four takeovers the guarding male that lost died soon afterward. These observations suggest that guarding males pursue a classical hawk strategy of "escalate until injured or victorious" (Maynard Smith and Parker 1976; Maynard Smith 1982). This strategy may be selectively advantageous because only large males become guarders, the mating success of guarders greatly exceeds that of non-guarders, egg mass areas are always few in number relative to the number of males in a colony, and in colonies with a small number of (wingless) males, the benefits of killing an opponent accrue directly to the guarding male (see Matthews 1975; Murray and Gerrard 1984). Alternatively, such a hawk tactic may be non-optimal (i.e., exhausted males should forbear territorial defence) but be maintained partially because of its simplicity; for example, aggressiveness may be inextricably tied to mating frequency, regardless of other contingencies.

Faced with an opponent that always escalates, non-guarding males can either immediately fight to the death, permanently adopt non-guarding status, or adopt non-guarding status, but occasionally challenge the guarding male. Immediate fights to the death are expected when there are no alternatives to fighting; Hoplothrips karnyi males have the option of sneaking. The data show that nonguarding males pursue either of the other two alternatives: small non-guarding males consistently sneak, whereas larger non-guarding males sneak, but periodically challenge the guarding male. Game theory reasoning predicts that challenges to guarding males, by males that lost in previous interactions, will not occur unless the asymmetries between contestants have actually or potentially changed since the last interaction. Eventual success of challengers may be affected by the costs of guarding; guarding males are more active than non-guarding males, frequently engage in fights, are frequently stabbed, and cannot feed without leaving their territory. These costs may, over time, create a fighting ability asymmetry favouring non- 
guarders. Moreover, if guarding males are limited in their ability to fertilise females, as suggested by their reverse-climb behaviour, then a resource value asymmetry favouring non-guarders also develops over time; non-guarding males (with a larger supply of sperm than guarding males) may have more to gain by winning a fight. Challenges may tend to follow matings by non-guarding males at oviposition sites because securing such matings indicates that fighting ability or resource value asymmetries have changed in their favour.

Thorough understanding of male mating strategies in Hoplothrips karnyi requires sperm competition studies, experimental manipulation of asymmetries in fighting ability, resource value, and ownership status, and data on mortality from fighting in natural populations. However, these observations indicate that lethal fighting in this species does not result from inadequacy or irrelevance of assessment mechanisms. In $H$. karnyi and other animals, lethal fighting is consistently associated with extreme localisation of resources and repeated interactions among the same individuals, both of which increase resource value and make severe fighting worthwhile (Hamilton 1979; Crespi 1986a). Thus the rarity of lethal fighting in nature probably reflects the exceptional conditions under which it evolves.

Acknowledgements. I would like to thank W.D. Hamilton for introducing me to the genus Hoplothrips, and R.D. Alexander, B.M. O'Connor, L. Vawter and R. Wrangham for helpful comments.

\section{References}

Ananthakrishnan TN (1979) Biosystematics of Thysanoptera. Ann Rev Entomol 24:159-183

Ananthakrishnan TN (1984) Bioecology of Thrips. Indira Publishing, Oak Park, Michigan

Aoki S, Makino S (1982) Gall usurpation and lethal fighting among fundatrices of the aphid Epipemphigus niisimae (Homoptera, Pemphigidae). Kontyu 50:365-376

Arak A (1983) Male-male competition and mate choice in anuran amphibians. In: Bateson PPG (ed) Mate choice. Cambridge University Press, Cambridge, pp 181-210

Austad SN (1983) A game-theoretical interpretation of male combat in the bowl and doily spider (Frontinella pyramitela). Anim Behav 31:59-73

Bode W (1978) Ultrastructure of the sternal glands of Thrips validus Uzel. Zoomorphologie 90:53-65

Clutton-Brock TH (1982) The functions of antlers. Behaviour 79: 108-124

Clutton-Brock TH, Albon SD, Gibson RM, Guinness FE (1979) The logical stag: adaptive aspects of fighting in red deer (Cervus elaphus L.). Anim Behav 27:211-225

Cowan DP (1984) Life history and male dimorphism in the mite Kennethiella trisetosa (Acarina: Winterschmidtiidae), and its symbiotic relationship with the wasp Ancistroceres antilope (Hymenoptera: Eumenidae). Ann Entomol Soc Am $77: 725-732$

Crespi BJ (1986a) Territoriality and fighting in a colonial thrips, Hoplothrips pedicularius, and sexual dimorphism in Thysanoptera. Ecol Entomol 11:119-130

Crespi BJ (1986b) Size assessment and alternative fighting tactics in Elaphrothrips tuberculatus (Insecta:Thysanoptera). Anim Behav 34:1324-1335

Davies NB (1978) Territorial defence in the speckled wood butterfly (Pararge aegeria): the resident always wins. Anim Behav 26:138-147

Davies NB, Halliday TR (1978) Deep croaks and fighting assessment in toads Bufo bufo. Nature 274:683-685

Dewsbury DA (1982) Ejaculate cost and male choice. Am Nat 119:601-610

Dewsbury DA, Sawrey DK (1984) Male capacity as related to sperm production, pregnancy initiation, and sperm competition in deer mice (Peromyscus maniculatus). Behav Ecol Sociobiol 16:37-47

Dominey W (1984) Alternative mating tactics and evolutionarily stable strategies. Am Zool 24:385-396

Eberhard WG (1982) Beetle horn dimorphism: making the best of a bad lot. Am Nat 119:420-426

Ewald PW (1985) Influence of asymmetries in resource quality and age on aggression and dominance in black-chinned hummingbirds. Anim Behav 33:705-719

Fox DJ, Guire KE (1976) Documentation for MIDAS. Statistical Research Laboratory, The University of Michigan, Ann Arbor

Gadgil M (1972) Male dimorphism as a consequence of sexual selection. Am Nat 106:574-580

Godfray HCJ (1987) The evolution of clutch size in parasitic wasps. Am Nat 129:221-233

Gwynne D (1984) Male mating effort, confidence of paternity, and insect sperm competition. In: Smith RL (ed) Sperm competition and the evolution of animal mating systems. Academic Press, New York, pp 117-150

Hamilton WD (1979) Wingless and fighting males in fig wasps and other insects. In: Blum MS, Blum NA (eds) Sexual selection and reproductive competition in insects. Academic Press, New York, pp 167-220

Kluge AG (1981) The life history, social organization, and parental behavior of Hyla rosenbergi, a nest-building gladiator frog. Misc Pub Mus Zool Univ Michigan 160:1-170

Krebs JR (1982) Territorial defence in the great tit (Parus major): do residents always win? Behav Ecol Sociobiol $11: 185-194$

Lewis T (1973) Thrips: their biology, ecology, and economic importance. Academic Press, New York

Matthews R (1975) Courtship in parasitic wasps. In: Price PW (ed) Evolutionary stratgies of parasitic insects and mites. Plenum Press, New York, pp 66-86

Maynard Smith J (1974) The theory of games and the evolution of animal conflicts. $J$ Theor Biol 47:209-222

Maynard Smith J (1982) Evolution and the theory of games. Cambridge University Press, Cambridge

Maynard Smith J, Parker GA (1976) The logic of asymmetric contests. Anim Behav 24:159-175

Maynard Smith J, Price GR (1973) The logic of animal conflict. Nature 246:15-18

McHugh T (1958) Social behavior of the American Buffalo. Zoologica 43:1-39

Murray MG, Gerrard R (1984) Conflict in the neighbourhood: models where close relatives are in direct competition. J Theor Biol 111:237-246

Nakatsuru K, Kramer DL (1982) Is sperm cheap? Limited male 
fertility and female choice in the Lemon Tetra (Pisces, Characidae). Science 216:753-754

Otronen M (1984) Male contests for territories and females in the fly Dryomyza anilis. Anim Behav 32:891-898

Parker GA (1974) Assessment strategy and the evolution of fighting behaviour. J Theor Biol 47:223-243

Parker GA, Rubenstein DI (1981) Role assessment, reserve strategy, and the acquisition of information in asymmetric animal contests. Anim Behav 29:221-240

Potter DA, Wrensch DL, Johnston DE (1976) Aggression and mating success in spider mites. Science 193:160-161

Ramer JD, Jensen TA, Hurst CJ (1983) Size-related variation in the advertisement call of Rana clamitans (Anura: Ranidae) and its effect on conspecific males. Copeia 1983:141-155

Rand AS, Rand WM (1976) Agonistic displays in nesting iguanas: a stochastic analysis of dispute settlement dominated by the minimization of energy costs. Z Tierpsychol 40:279-299

Riechert SE (1978) Game spiders play: behavioral variability in territorial disputes. Behav Ecol Sociobiol 3:135-162

Robinson SK (1985) Fighting and assessment in the yellowrumped cacique (Cacicus cela). Behav Ecol Sociobiol $18: 39-44$

Rubenstein DI (1980) On the evolution of alternative mating strategies. In: Staddon JER (ed) Limits to action: the allocation of individual behavior. Academic Press, New York

Seeley TD (1985) Honeybee ecology. Princeton Univ Press, New Jersey

Sigurjonsdottir H, Parker GA (1981) Dung fly struggles: evidence for assessment strategy. Behav Ecol Sociobiol $8: 219-230$
Slater PJB (1973) Describing sequences of behavior. In: Bateson PPG, Klopfer PH (eds) Perspectives in ethology, vol. 1. Plenum Press, New York, pp 131-153

Snedecor GW, Cochran WG (1980) Statistical methods, 7th ed. Iowa State Univ Press, Ames, Iowa

Stannard LJ (1957) The phylogeny and classification of the North American genera of the suborder Tubulifera (Thysanoptera). Ill. Biol. Monographs 25. University of Illinois Press, Urbana

Stannard LJ (1968) The thrips, or Thysanoptera of Illinois. Ill Nat Hist Surv Bull 29:215-552

Suter RB, Keiley M (1984) Agonistic interactions between male Frontinella pyramitella (Aranae, Linyphiidae). Behav Ecol Sociobiol 15:1-7

Thornhill R (1984) Fighting and assessment in Harpobittacus scorpionflies. Evolution 38:204-214

Thornhill R, Alcock J (1983) The evolution of insect mating systems. Harvard Univ. Press, Cambridge, Mass

Tiemann DL (1967) Observations on the natural history of the western banded glowworm Zarhipis integripennis (LeConte) (Coleoptera:Phengodidae), Proc Cal Acad Sci $35: 235-264$

Timms S, Ferro DN, Emberson RM (1980) Selective advantage of pleomorphic male Sancassania berlesei (Michael) (Acari: Acaridae). Int J Acarol 6:97-102

Van Den Assem J, Gijswijt MJ, Nubel BK (1980) Observations on courtship and mating strategies in a few species of parasitic wasps (Chalcidoidea). Neth J Zool 30:208-227

Wilkinson PF, Shank CC (1976) Rutting-fight mortality among musk oxen on Banks Island, Northwest Territories, Canada. Anim Behav 24:756-758 